\title{
Caffeine enhances micturition through neuronal activation in micturition centers
}

\author{
YOUNG-SAM CHO $^{1}$, IL-GYU KO ${ }^{2}$, SUNG-EUN KIM ${ }^{2}$, LAKKYONG HWAN ${ }^{2}$, MAL-SOON SHIN $^{2}$, \\ CHANG-JU KIM ${ }^{2}$, SANG-HOON KIM ${ }^{3}$, JUN-JANG JIN ${ }^{4}$, JUN-YOUNG CHUNG ${ }^{5}$ and KHAE-HAWN KIM ${ }^{6}$ \\ ${ }^{1}$ Department of Urology, Kangbuk Samsung Medical Center, Sungkyunkwan University School of Medicine, Seoul 110-746; \\ ${ }^{2}$ Department of Physiology, College of Medicine, Kyung Hee University, Seoul 130-701; \\ ${ }^{3}$ Department of Physical Education, Graduate School of Education, Sangmyung University, Seoul 110-743; \\ ${ }^{4}$ Department of Physical Activity Design, College of Science, Hanseo University, Seosan 356-706; \\ ${ }^{5}$ Department of Anesthesiology and Pain Medicine, Gangdong Kyung Hee Hospital, \\ College of Medicine, Kyung Hee University, Seoul 134-727; ${ }^{6}$ Department of Urology, \\ Gachon University Gil Medical Center, Incheon 405-760, Republic of Korea
}

Received August 21, 2013; Accepted May 28, 2014

DOI: $10.3892 / \mathrm{mmr} .2014 .2646$

\begin{abstract}
Caffeine may promote incontinence through its diuretic effect, particularly in individuals with underlying detrusor overactivity, in addition to increasing muscle contraction of the bladder smooth muscle. Caffeine may also affect bladder function via central micturition centers, including the medial preoptic area, ventrolateral periaqueductal gray, and pontine micturition center. However, the biochemical mechanisms of caffeine in central micturition centers affecting bladder function remain unclear. In the present study, the effects of caffeine on the central micturition reflex were investigated by measuring the degree of neuronal activation, and by quantifying nerve growth factor (NGF) expression in rats. Following caffeine administration for 14 days, a urodynamic study was performed to assess the changes to bladder function. Subsequently, immunohistochemical staining to identify the expression of c-Fos and NGF in the central micturition areas was performed. Ingestion of caffeine increased bladder smooth muscle contraction pressure and time as determined by cystometry. Expression levels of c-Fos and NGF in all central micturition areas were significantly increased following the administration of caffeine. The effects on contraction pressure and time were the most potent and expression levels of c-Fos and NGF were greatest at the lowest dose of caffeine. These results suggest that caffeine facilitates bladder instability
\end{abstract}

Correspondence to: Professor Khae-Hawn Kim, Department of Urology, Gachon University Gil Medical Center, 1198 Guwol-dong, Namdong-gu, Incheon 405-760, Republic of Korea

E-mail: kimcho99@gilhospital.com

Key words: caffeine, central micturition center, c-Fos, nerve growth factor, neuronal activation through enhancing neuronal activation in the central micturition areas.

\section{Introduction}

Caffeine (3,7-dihydro-1,3,7-trimethyl-1H-purine-2,6-dione) is regularly consumed by $>85 \%$ of adults in the United States due to its natural presence in coffee and tea, and is used as an additive in numerous commercially available beverages (1). With such prevalence, caffeine has long been implicated as a source of irritation to the urinary bladder. This presumption is supported by a recent prospective, longitudinal study that indicated an association between caffeine-containing beverage consumption and urge incontinence in females (2). Regardless, there is a paucity of scientific evidence directly linking caffeine ingestion to the development or persistence of clinical lower urinary tract symptoms (LUTS) or urodynamically demonstrable bladder dysfunction. There are two potential biological mechanisms underlying the bladder-irritant effects of caffeine: i) Caffeine may promote urinary incontinence through a diuretic effect, particularly among individuals with underlying detrusor overactivity (2); in a previous study of patients with overactive bladder symptoms, total urine volume was increased in the caffeine consumption group, confirming the diuretic effect of caffeine (3), and severity of nocturia was also demonstrated to be associated with caffeine consumption (4). ii) Caffeine led to increased muscle contraction velocity in bladder smooth muscle through an increase in the release of intracellular calcium from storage sites in a study by Lee et al (5).

Generally, the storage and excretion ability of the lower urinary tract system is regulated by complex systemic control of neural pathways in the CNS and peripheral nervous system. Neuroanatomical tracing studies have revealed that the urinary bladder and external urethral sphincter are innervated directly or indirectly from multiple CNS regions, including the pontine micturition center (PMC), locus coeruleus, hypothalamus 
(including the preoptic area), and spinal cord (6). Using a positron emission tomography scanner, increased blood flow to the dorsomedial pons, periaqueductal gray (PAG), hypothalamus, and cerebral cortex have been observed during micturition (7). Additionally, bladder hyperactivity has been indicated to induce chemical changes in the spinal cord (8). In particular, caffeine may produce certain effects on the CNS, thereby affecting bladder function, as caffeine has been demonstrated in animal studies to penetrate the blood-brain barrier $(9,10)$. Furthermore, there exist diverse fundamental biochemical mechanisms underlying the molecular and cellular actions of caffeine in the brain (11). Among them, various biological factors potentially underlie micturitional dysfunction.

The transcription factor c-Fos is encoded by the immediately early gene c-Fos; hereafter, c-Fos expression is used to represent the presence of neuronal activity (12). Previous studies demonstrate that stimulation of the urinary bladder increases expression of c-Fos-immunoreactive neurons in the PAG, PMC and spinal cord $(13,14)$.

Another important modulator of voiding is nerve growth factor (NGF). NGF is produced by urothelial tissue and smooth muscle cells and is one of the neurotrophic factors required for the maintenance of neuronal survival (15). Clinical and experimental data have indicated a direct association between increased levels of NGF in the bladder, urethral tissue and urine, and LUTS, including overactive bladder syndrome, interstitial cystitis, urinary incontinence and painful inflammatory conditions $(16,17)$.

In the present study, the association between caffeine consumption and voiding dysfunction was investigated in light of urodynamic action. The effects of caffeine on the central micturition reflex were also examined by investigating the incidence of expression of c-Fos and NGF in the central micturition areas, including the medial preoptic area (MPA), ventrolateral (vl)PAG and PMC, in rats.

\section{Materials and methods}

Experimental animals and treatment. All experimental procedures were performed in accordance with the animal care guidelines of the National institutes of Health and the Korean Acadamy of Medical Sciences. This study was approved by the Kyung Hee University Institutional Animal Care and Use Committee (Seoul, Korea, KHUASP-13-038). Adult female Sprague-Dawley rats, weighing 250 \pm 10 g (9 weeks old), were obtained from a commercial breeder (Orient Co., Seoul, Korea). All experimental procedures were performed in accordance with the animal care guidelines of the National Institutes of Health and the Korean Academy of Medical Sciences. Each experimental animal was housed under controlled temperature $\left(23 \pm 2^{\circ} \mathrm{C}\right)$ and lighting (08:00-20:00 h) conditions with food and water made available ad libitum during the experiments. The animals were randomly divided into four groups as follows ( $\mathrm{n}=8$ in each group): The control group; the $10 \mathrm{mg} / \mathrm{kg}$ caffeine-treated group; the $50 \mathrm{mg} / \mathrm{kg}$ caffeine-treated group; and the $100 \mathrm{mg} / \mathrm{kg}$ caffeine-treated group. The rats in the caffeine-treated groups received caffeine orally (Sigma-Aldrich, St. Louis, MO, USA) once a day for 14 days, and the rats in the control group received an equal volume of distilled water for the same time period.
Urodynamic study (cystometry). Bladder function of the rats was evaluated by cystometry 14 days after the first treatment, according to a previously described method (18). The rats were anesthetized intraperitoneally with Zoletil $50^{\circledR}$ (10 mg/kg; Virbac, Carros, France). Following low midline incision, the bladders were dissected and a sterile polyethylene catheter (PE50; Ref. 800; SIMS Portex Ltd., Kent, UK) was inserted into the bladder dome. To monitor the pressure, the catheter was connected to a pressure transducer (Harvard Apparatus, Holliston, MA, USA) and syringe pump (Harvard Apparatus) via a 3-way stopcock (Insung Medical Co. Ltd., Seoul, Korea) to record intravesical pressure and to infuse saline into the bladder. Once the bladder was emptied, cystometry was performed with infusion of $0.5 \mathrm{ml}$ saline. The contraction pressure and contraction time of the bladder were recorded using Labscribe software version 1.801 (iWorx Systems Inc., Dover, NH, USA).

Tissue preparation. All rats were sacrificed immediately following the cystometry using Zoletil $50^{\circledR}(10 \mathrm{mg} / \mathrm{kg}$; Virbac, Carros, France). The animals were perfused transcardially with $50 \mathrm{mM}$ phosphate-buffered saline (PBS), followed by 4\% paraformaldehyde in $100 \mathrm{mM}$ sodium phosphate buffer at $\mathrm{pH}$ 7.4. The brain was harvested, postfixed in the same fixative overnight, and transferred into a $30 \%$ sucrose solution for cryoprotection the following day. Serial coronal sections $(40-\mu \mathrm{m}$ thick) were made with a freezing microtome (CM1510-3; Leica Microsystems Ltd., Nussloch, Germany). Ten sections on average per region were obtained from each rat. For immunohistochemical analyses, the PMC was denoted as the region spanning bregma -9.68 to $-9.80 \mathrm{~mm}$; the vlPAG was the region spanning bregma -7.64 to $-8.00 \mathrm{~mm}$; and the MPA was the region spanning from bregma -0.26 to $0.80 \mathrm{~mm}(18)$.

Immunohistochemistry for c-Fos and NGF. Immunohistochemical staining was conducted using a previously described method $(12,18)$. Free-floating tissue sections were incubated overnight with rabbit anti-c-Fos and mouse anti-NGF antibodies (Santa Cruz Biotechnology, Inc., Santa Cruz, CA, USA) at a dilution of 1:1,000, and the sections were then incubated for $1 \mathrm{~h}$ with biotinylated anti-rabbit for $\mathrm{c}-\mathrm{Fos}$ and anti-mouse secondary antibody for NGF (Vector Laboratories, Burlingame, CA, USA). Next, the sections were incubated with avidin-biotin-peroxidase complex (Vector Laboratories) for $1 \mathrm{~h}$ at room temperature. Immunoreactivity was visualized by incubating the sections in a solution consisting of $0.05 \%$ 3,3'-diaminobenzidine and $0.01 \% \mathrm{H}_{2} \mathrm{O}_{2}$ in $50 \mathrm{mM}$ Tris buffer ( $\mathrm{pH}$ 7.6) for $\sim 3 \mathrm{~min}$. These sections were then washed three times with PBS and mounted onto gelatin-coated slides. The slides were air-dried overnight at room temperature, and coverslips were mounted using Permount ${ }^{\mathrm{TM}}$ Mounting medium (Thermo Fisher Scientific, Waltham, MA, USA).

Data analysis. The numbers of c-Fos-positive and NGF-positive cells in the MPA, vlPAG, and PMC regions were counted hemilaterally, using a light microscope (BX51TF; Olympus, Tokyo, Japan). An Image-Pro Plus (Media Cyberbetics, Inc., Silver Spring, MD, USA) computer-assisted image analysis system attached to the 
A
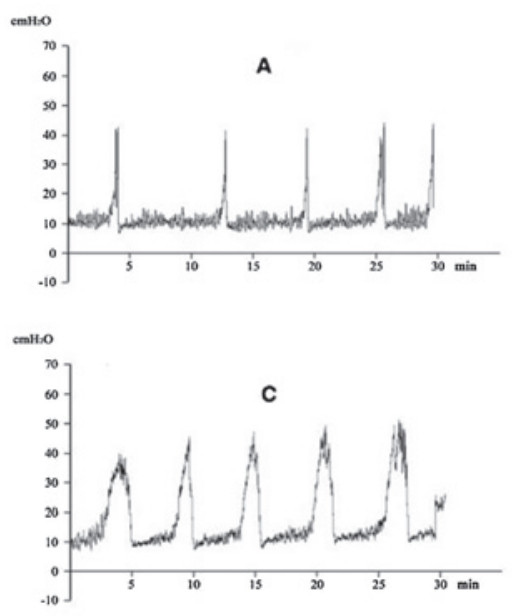

B

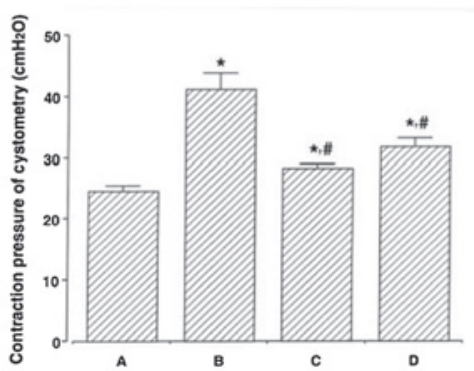

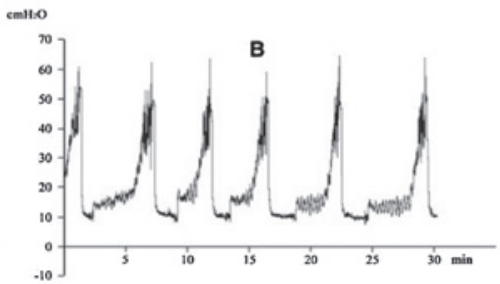
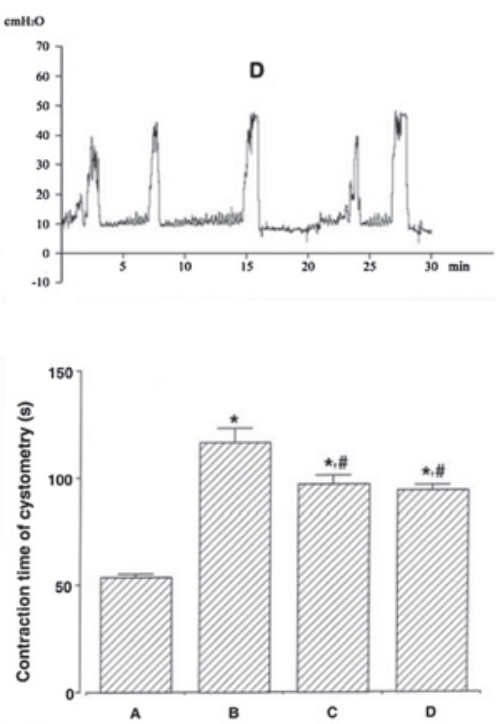

Figure 1. Effect of caffeine on contraction pressure and time as measured by cystometry. (A) Cystometry graph for each group. (B) Analysis of contraction pressure (left) and contraction time (right) in each group. The results are presented as the mean \pm standard error of the mean. ${ }^{*} \mathrm{P}<0.05 \mathrm{vs}$. the control group. ${ }^{\#} \mathrm{P}<0.05$ vs. the $10 \mathrm{mg} / \mathrm{kg}$ caffeine-treated group. A, control; B, $10 \mathrm{mg} / \mathrm{kg}$ group; C, $50 \mathrm{mg} / \mathrm{kg}$ group; D, $100 \mathrm{mg} / \mathrm{kg}$ group.

light microscope was used to measure the areas of the MPA, vlPAG and PMC regions from each slice. Statistical analysis was performed by one-way analysis of variance followed by Duncan's post-hoc test, and all data are expressed as the mean \pm standard errors of the mean. $\mathrm{P}<0.05$ was considered to indicate a statistically significant difference.

\section{Results}

Effects of caffeine on contraction pressure and time in the bladder. The contraction pressures and times obtained by cystometry are presented in Fig. 1. The results indicated that caffeine consumption increased contraction pressure and time significantly $(\mathrm{P}<0.05$, vs. control). The effects of caffeine on contraction pressure and contraction time were most potent at the lowest dose of caffeine $(10 \mathrm{mg} / \mathrm{kg}, \mathrm{P}<0.05,50$ and $100 \mathrm{mg} / \mathrm{kg}$ vs. $10 \mathrm{mg} / \mathrm{kg}$ ).

Effects of caffeine on c-Fos expression in the central micturition areas. Enhancement of c-Fos-positive cells in the central micturition areas (MPA, vlPAG and PMC) is presented in Fig. 2. The results indicated that c-Fos expression levels in the central micturition areas were increased by caffeine administration ( $\mathrm{P}<0.05$, vs. control), and the lowest dose of caffeine $(10 \mathrm{mg} / \mathrm{kg})$ enhanced c-Fos expression to the greatest extent $(\mathrm{P}<0.05,50$ and $100 \mathrm{mg} / \mathrm{kg}$ vs. $10 \mathrm{mg} / \mathrm{kg})$.

Effects of caffeine on NGF expression in the central micturition areas. Enhancement of NGF-positive cells in the central micturition areas (MPA, vlPAG and PMC) is presented in Fig. 3. NGF expression in the central micturition areas increased with caffeine administration ( $\mathrm{P}<0.05$, vs. control), and the lowest dose of caffeine $(10 \mathrm{mg} / \mathrm{kg})$ enhanced NGF expression to the greatest extent $(\mathrm{P}<0.05,50$ and $100 \mathrm{mg} / \mathrm{kg}$ vs. $10 \mathrm{mg} / \mathrm{kg})$.

\section{Discussion}

It is widely agreed that human behaviors such as smoking and the ingestion of dietary irritants, including caffeine, may incite and exacerbate LUTS, and reduce the efficacy of potential treatments of LUTS. Indeed, caffeine may have a diuretic effect in certain individuals but may also affect the bladder by increasing detrusor pressure and promoting detrusor muscle excitability $(19,20)$. However, epidemiological and clinical cohort studies have reported mixed results regarding the association between urge incontinence and caffeine and fluid intake in females $(21,22)$. In a study investigating the influence of caffeine in overactive bladders, caffeine caused diuresis and reduced the threshold of urge sensation at the filling phase, with an increase in flow rate and voided volume. A previous clinical trial investigated the effects of caffeine on bladder function and reported similar results (23). These results indicate that caffeine has the ability to aggravate urgency and increase the frequency of urination by making the bladder more sensitive to bladder filling (23). Involuntary detrusor contraction and increased bladder pressure and time are also observed in several voiding disorders, including overactive bladder and bladder outlet obstruction $(24,25)$. 
A
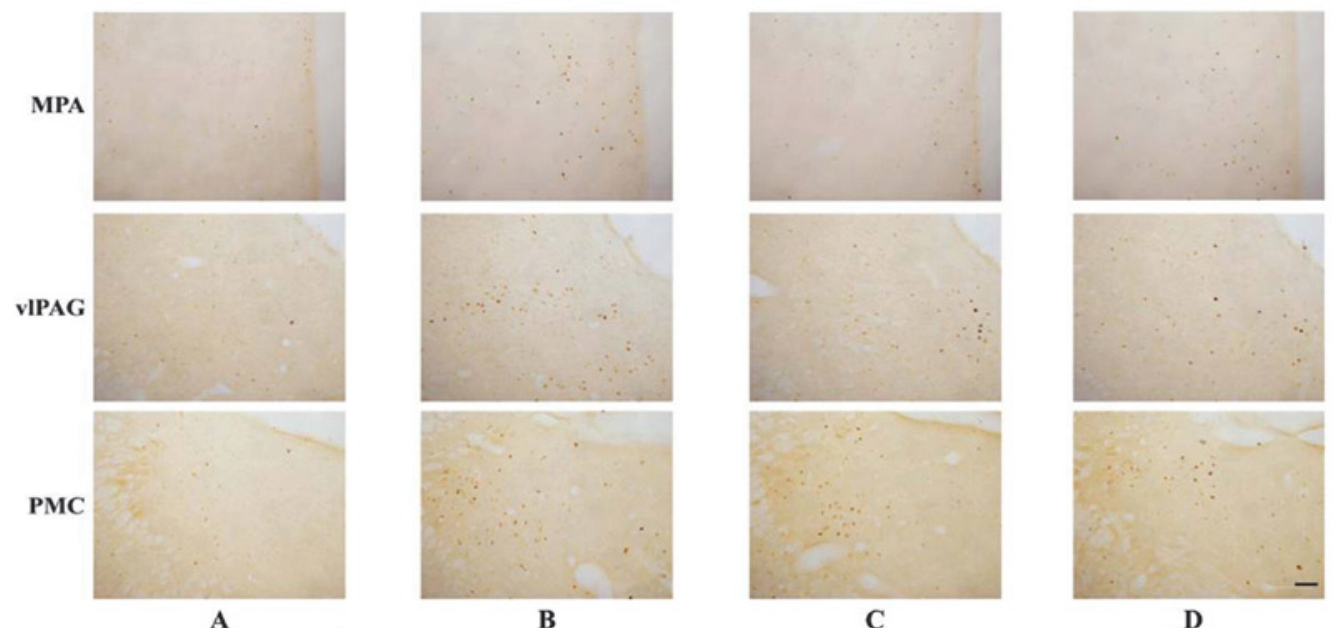

B

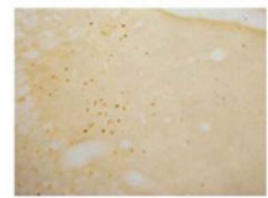

C

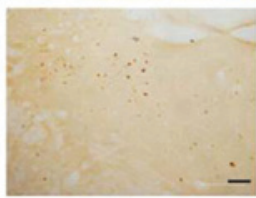

D

B
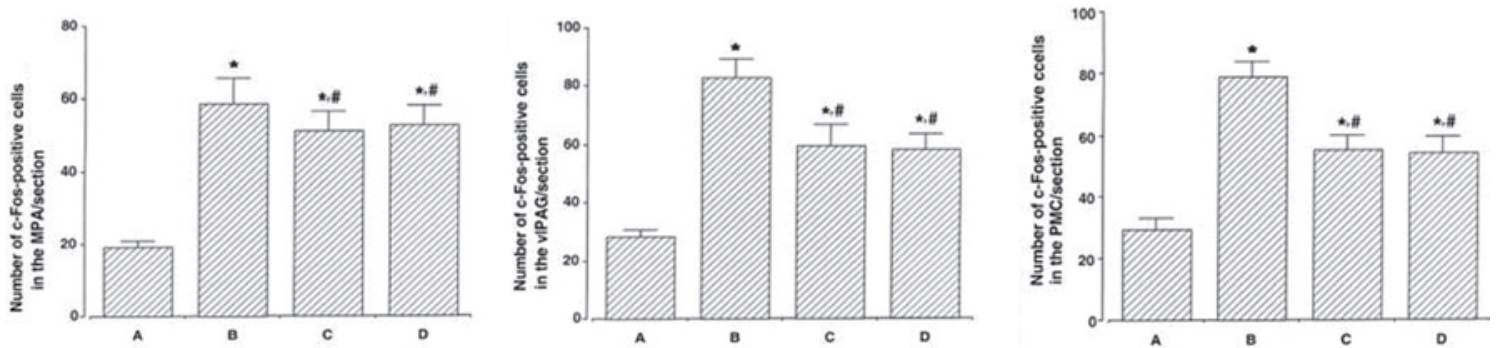

Figure 2. Effect of caffeine on c-Fos expression in the central micturition areas. (A) Photomicrographs of c-Fos-positive cells in the central micturition areas. Scale bar represents $200 \mu \mathrm{m}$. (B) Number of c-Fos-positive cells in each group. The results are presented as the mean \pm standard error of the mean. ${ }^{*} \mathrm{P}<0.05$ vs. the control group. " $\mathrm{P}<0.05$ vs. the $10 \mathrm{mg} / \mathrm{kg}$ caffeine-treated group. A, control; B, $10 \mathrm{mg} / \mathrm{kg}$ group; C, $50 \mathrm{mg} / \mathrm{kg}$ group; D, $100 \mathrm{mg} / \mathrm{kg}$ group. MPA, medial preoptic area; vlPAG, ventrolateral periaqueductal gray; PMC, pontine micturition center.

A
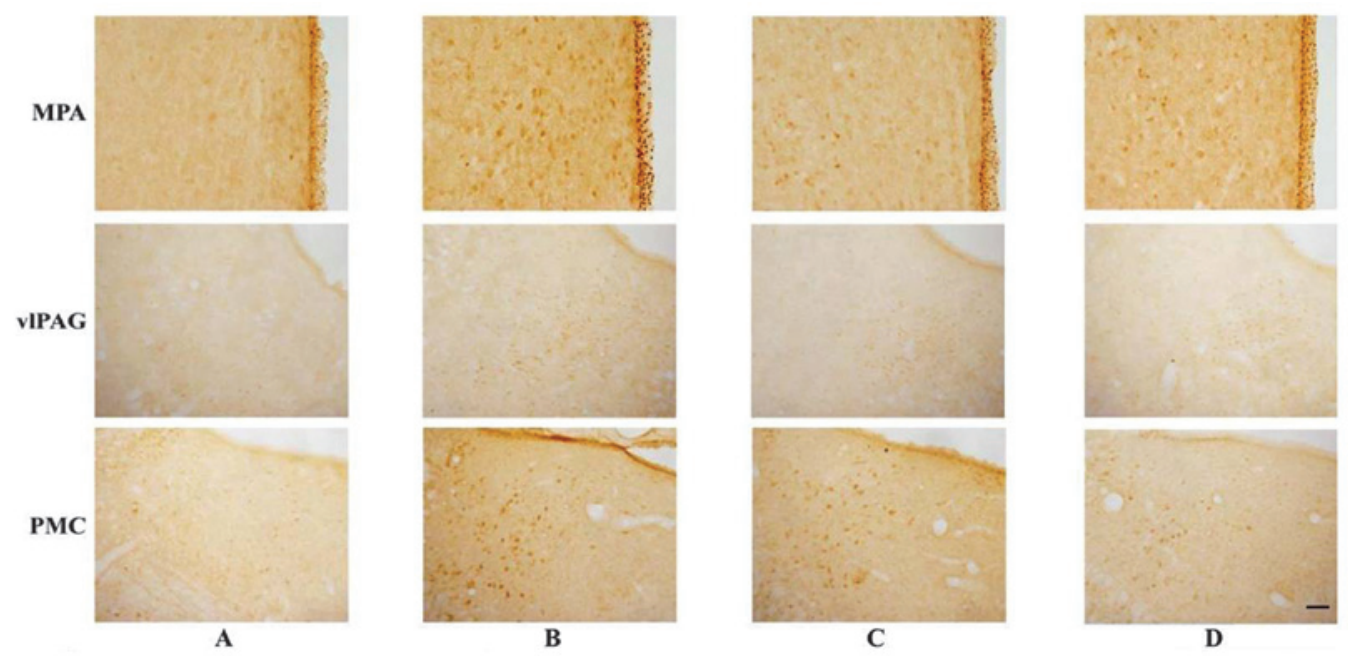

B
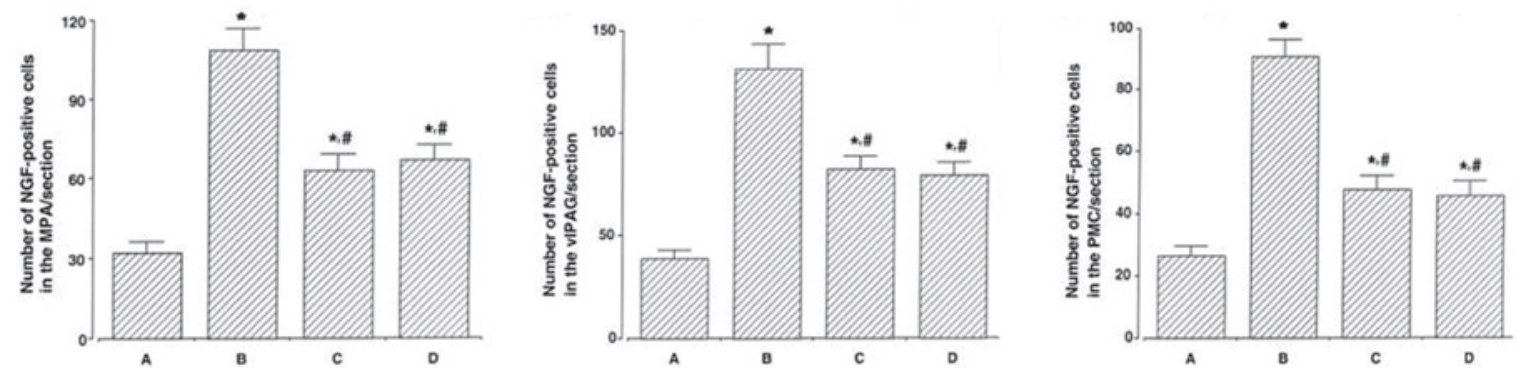

Figure 3. Effect of caffeine on NGF expression in the central micturition areas. (A) Photomicrographs of NGF-positive cells in the central micturition areas. The scale bar represents $200 \mu \mathrm{m}$. (B) Number of NGF-positive cells in each group. The results are presented as the mean \pm standard error of the mean. ${ }^{*} \mathrm{P}<0.05$ vs. the control group. ${ }^{~} \mathrm{P}<0.05$ vs. the $10 \mathrm{mg} / \mathrm{kg}$ caffeine-treated group. A, control; B, $10 \mathrm{mg} / \mathrm{kg}$ group; C, $50 \mathrm{mg} / \mathrm{kg}$ group; D, $100 \mathrm{mg} / \mathrm{kg}$ group. MPA, medial preoptic area; vlPAG, ventrolateral periaqueductal gray; PMC, pontine micturition center; NGF, nerve growth factor. 
These studies therefore indicate that caffeine deteriorates bladder function and as a result, may induce an overactive bladder, urge incontinence, and unintended bladder contractions due to detrusor instability.

In general, bladder functions associated with filling and storage processes require accommodation to increased urine volumes at low intravesical pressure with appropriate sensation in order for the urethral sphincter to remain closed during the increased abdominal pressure and involuntary bladder contraction (24). Through this mechanism, normal detrusor function allows urinary storage during the filling phase with little or no change to bladder pressure. Urodynamic study is the only appropriate method to evaluate lower urinary tract function and how this relates to LUTS. Urodynamic study should be used to determine the underlying pathophysiology or cause of LUTS, thereby allowing more rational treatment of voiding dysfunction diseases such as overactive bladder, urge incontinence and bladder outlet obstruction. In a previous study that investigated the effect of caffeine on voiding function in normal mice, caffeine administration resulted in detrusor overactivity and increased bladder sensory signaling (26). There were clear differences in cytometric parameters of animals that ingested caffeine compared with those that did not receive caffeine. In the present study, a urodynamic study was performed in normal rats in order to evaluate the effects of caffeine on normal bladder function; and detrusor smooth muscle contraction pressure and time was measured following caffeine administration. A significant increase in bladder contraction pressure and time were observed following the administration of caffeine.

The PMC is important in the control of urinary bladder function and there is a supraspinal switching center that regulates the storage and elimination of urine (27). The PAG and MPA of the hypothalamus are associated with the PMC (6) and the PAG-PMC projection is considered to take part in the micturition reflex. In addition, the PMC is densely innervated by the MPA (7), and the MPA sends projections to the PMC that synapse onto neurons directly though projections to the spinal cord (6). The vlPAG acts as a central sensorimotor integrative relay of the micturition reflex via the reception of sensory information concerning bladder fullness and the direct projection to the PMC (7), so neurons in the PAG regulate the micturition reflex in both animals and humans and lesions in the PAG cause severe urinary dysfunction $(7,28)$.

c-Fos expression is used as a marker of stimuli-induced changes in the metabolic activity of neurons (29). As demonstrated by Gayton and Pasaro (30) treatment of premature neonates with caffeine may alleviate apnea; they reported an increase in c-Fos-positive labeled cells in the anterior hypothalamic area, ventromedial hypothalamic nucleus, parabrachial complex and ventrolateral medulla (30). In another study, stimulation of the lower urinary tract was implicated to be the cause of changes in neuronal activity in micturition centers such as the PMC, PAG and MPA (31). Stimulation of the bladder has also been demonstrated to increase the number of c-Fos immunoreactive neurons in the PAG and PMC (14). In the present study, it was inferred that the caffeine-induced increase in c-Fos expression strongly stimulated neuronal activity in the central micturition areas.
A previous study demonstrated that acute intraperitoneal injection of caffeine increased locomotion and expression levels of NGF inducible A gene mRNA, a marker of neuronal activity, in the brain (32). Elevated NGF content has been observed in the urine of patients with interstitial cystitis and painful bladder contractions (33), and overexpression of NGF in the bladder and urethra is associated with disability of micturition in patients with urinary incontinence (34). Subsequent biochemical studies have suggested that NGF mediates afferent neuronal plasticity in the bladder following partial urethral obstruction in female rats (34). Increased NGF levels in the bladder or vesical afferent neuronal pathways may induce overactive bladder symptoms, incontinence, and c-fiber hyperexcitability (35). NGF triggers neuronal excitability through induction of sodium channels (36). In addition to modulation of neuronal cell survival, proliferation and differentiation, NGF is known to modulate neuronal excitability (37). In the present study, a caffeine-induced increase in NGF expression strongly stimulated neuronal activity in the central micturition areas.

In light of all evidence, the results of the current study suggest that caffeine facilitates bladder instability through enhancing neuronal activation in the neuronal micturition centers. Therefore, caffeine consumption may have a negative effect on voiding symptoms, and should be considered as an aggravating factor when treating patients with LUTS.

\section{References}

1. Anderson BL, Juliano LM and Schulkin J: Caffeine's implications for women's health and survey of obstetrician-gynecologists' caffeine knowledge and assessment practices. J Womens Health (Larchmt) 18: 1457-1466, 2009.

2. Jura YH, Townsend MK, Curhan GC, Resnick NM and Grodstein F: Caffeine intake, and the risk of stress, urgency and mixed urinary incontinence. J Urol 185: 1775-1780, 2011.

3. Lohsiriwat S, Hirunsai M and Chaiyaprasithi B: Effect of caffeine on bladder function in patients with overactive bladder symptoms. Urol Ann 3: 14-18, 2011.

4. Liao YM, Dougherty MC, Biemer PP, Liao CT, Palmer MH, Boyington AR and Connolly A: Factors related to lower urinary tract symptoms among a sample of employed women in Taipei. Neurourol Urodyn 27: 52-59, 2008.

5. Lee JG, Wein AJ and Levin RM: The effect of caffeine on the contractile response of the rabbit urinary bladder to field stimulation. Gen Pharmacol 24: 1007-1011, 1993.

6. Rickey LM, Sarkey S and DonCarlos LL: Estrogen-sensitive projections from the medial preoptic area to the dorsal pontine tegmentum, including Barrington's nucleus, in the rat. Neurourol Urodyn 27: 440-445, 2008.

7. Blok BFM and Holstege G: Direct projections from the periaqueductal gray to the pontine micturition center (M-region). An anterograde and retrograde tracing study in the cat. Neurosci Lett 166: 93-96, 1994.

8. de Groat WC and Yoshimura N: Mechanisms underlying the recovery of lower urinary tract function following spinal cord injury. Prog Brain Res 152: 59-84, 2006.

9. Lachance MP, Marlowe C and Waddell WJ: Autoradiographic disposition of [1-methyl-14C]- and [2-14C]caffeine in mice. Toxicol Appl Pharmacol 71: 237-241, 1983.

10. Tanaka H, Nakazawa K, Arima M and Iwasaki S: Caffeine and its dimethylxanthines and fetal cerebral development in rat. Brain Dev 6: 355-361, 1984.

11. Pelligrino DA, Xu HL and Vetri F: Caffeine and the control of cerebral hemodynamics. J Alzheimers Dis 20 (Suppl 1): S51-S62, 2010.

12. Seo JH, Kim TW, Kim CJ, Sung YH and Lee SJ: Treadmill exercise during pregnancy ameliorates post-traumatic stress disorder-induced anxiety-like responses in maternal rats. Mol Med Rep 7: 389-395, 2013. 
13. Dinis P, Charrua A, Avelino A and Cruz F: Intravesical resiniferatoxin decreases spinal c-fos expression and increases bladder volume to reflex micturition in rats with chronic inflamed urinary bladders. BJU Int 94: 153-157, 2004.

14. Kavia RB, Dasgupta R and Fowler CJ: Functional imaging and the central control of the bladder. J Comp Neurol 493: 27-32, 2005.

15. Steers WD and Tuttle JB: Mechanisms of Disease: the role of nerve growth factor in the pathophysiology of bladder disorders. Nat Clin Pract Urol 3: 101-110, 2006.

16. Lowe EM, Anand P, Terenghi G, Williams-Chestnut RE, Sinicropi DV and Osborne JL: Increased nerve growth factor levels in the urinary bladder of women with idiopathic sensory urgency and interstitial cystitis. Br J Urol 79: 572-577, 1997.

17. Kuo HC, Liu HT and Chancellor MB: Urinary nerve growth factor is a better biomarker than detrusor wall thickness for the assessment of overactive bladder with incontinence. Neurourol Urodyn 29: 482-487, 2010.

18. Kim SE, Shin MS, Kim CJ, Park JH, Chung KJ, Jung H, Kim KH, Lee JH and Ko IG: Effects of tamsulosin on urinary bladder function and neuronal activity in the voiding centers of rats with cyclophosphamide-induced overactive bladder. Int Neurourol J 16: 13-22, 2012.

19. Creighton SM and Stanton SL: Caffeine: does it affect your bladder? Br J Urol 66: 613-614, 1990.

20. Arya LA, Myers DL and Jackson ND. Dietary caffeine intake and the risk for detrusor instability: a case-control study. Obstet Gynecol 96: 85-89, 2000

21. Bortolotti A, Bernardini B, Colli E, Di Benedetto P, Giocoli Nacci G, Landoni M, Lavezzari M, Pagliarulo A, Salvatore S, von Heland M, Parazzini F and Artibani W: Prevalence and risk factors for urinary incontinence in Italy. Eur Urol 37: 30-35, 2000.

22. Tettamanti G, Altman D, Pedersen NL, Bellocco R, Milsom I and Iliadou AN: Effects of coffee and tea consumption on urinary incontinence in female twins. BJOG 118: 806-813, 2011.

23. Tomlinson BU, Dougherty MC, Pendergast JF, Boyington AR, Coffman MA and Pickens SM: Dietary caffeine, fluid intake and urinary incontinence in older rural women. Int Urogynecol J Pelvic Floor Dysfunct 10: 22-28, 1999.

24. Fowler CJ: Integrated control of lower urinary tract - clinical perspective. Br J Pharmacol 147 (Suppl 2): S14-S24, 2006.

25. Jun JH, Kang HJ, Jin MH, Lee HY, Im YJ, Jung HJ and Han SW: Function of the cold receptor (TRPM8) associated with voiding dysfunction in bladder outlet obstruction in rats Int Neurourol J 6: 69-76, 2012.

26. Kershen R, Mann-Gow T, Yared J, Stromberg I and Zvara P: Caffeine ingestion causes detrusor overactivity and afferent nerve excitation in mice. J Urol 188: 1986-1992, 2012.
27. Blok BFM and Holstege G: The pontine micturition center in rat receives direct lumbosacral input. An ultrastructural study. Neurosci Lett 282: 29-32, 2000.

28. Sakakibara R, Hattori T, Yasuda K, Yamanishi T, Tojo M and Mori M: Micturitional disturbance in Wernicke's encephalopathy. Neurourol Urodyn 16: 111-115, 1997.

29. Dragunow M and Faull R: The use of c-fos as a metabolic marker in neuronal pathway tracing. J Neurosci Methods 29: 261-265, 1989.

30. Gaytan SP and Pasaro R: Neonatal caffeine treatment up-regulates adenosine receptors in brainstem and hypothalamic cardio-respiratory related nuclei of rat pups. Exp Neurol 237: 247-259, 2012.

31. Bon K, Lantéri-Minet M, de Pommery J, Michiels JF and Menétrey D: Cyclophosphamide cystitis as a model of visceral pain in rats. A survey of hindbrain structures involved in visceroception and nociception using the expression of c-Fos and Krox-24 proteins. Exp Brain Res 108: 404-416, 1996.

32. Svenningsson P, Nomikos GG and Fredholm BB: The stimulatory action and the development of tolerance to caffeine is associated with alterations in gene expression in specific brain regions. J Neurosci 19: 4011-4022, 1999.

33. Okragly AJ, Niles AL, Saban R, Schmidt D, Hoffman RL, Warner TF, Moon TD, Uehling DT and Haak-Frendscho M: Elevated tryptase, nerve growth factor, neurotrophin-3 and glial cell line-derived neurotrophic factor levels in the urine of interstitial cystitis and bladder cancer patients. J Urol 161: 438-442, 1999.

34. Furuta A, Kita M, Suzuki Y, Egawa S, Chancellor MB, de Groat WC and Yoshimura N: Association of overactive bladder and stress urinary incontinence in rats with pudendal nerve ligation injury. Am J Physiol Regul Integr Comp Physiol 294: R1510-R1516, 2008.

35. Yi CR, Wei ZQ, Deng XL, Sun ZY, Li XR and Tian CG: Effects of coffee and caffeine on bladder dysfunction in streptozotocin-induced diabetic rats. Acta Pharmacol Sin 27: 1037-1043, 2006.

36. Toledo-Aral JJ, Brehm P, Halegoua S and Mandel G: A single pulse of nerve growth factor triggers long-term neuronal excitability through sodium channel gene induction. Neuron 14: 607-611, 1995

37. Jia Z, Bei J, Rodat-Despoix L, Liu B, Jia Q, Delmas P and Zhang H: NGF inhibits M/KCNQ currents and selectively alters neuronal excitability in subsets of sympathetic neurons depending on their M/KCNQ current background. J Gen Physiol 131: 575-587, 2008 